\title{
Adaptation and Stability Analysis of ICARDA Durum Wheat Elites across 18 Countries
}

\author{
F. M. Bassi` and M. Sanchez-Garcia
}

\begin{abstract}
Durum wheat (Triticum durum Desf.) is the 10th most important crop in the world, and its cultivation occurs on a vast array of international agroenvironments. However, its wide international adaptation is only marginally documented. Here, 24 durum wheat genotypes comprising elites from the ICARDA breeding program and commercial checks were assessed at 27 field stations located in 18 countries. Analysis of variance revealed significant environment, genotype, and genotype $\times$ environment (GxE) effects for phenology, height, grain yield, and grain size, with genotype and GxE explaining 1 and $9.6 \%$ of the total grain yield variation, respectively. Heritability was recorded at 0.6 for grain yield. Only late maturity and extended grain filling-period had a negative effect on grain yield $(r=-0.67, p<0.01)$. A matrix of correlation between traits was used for hierarchical clustering to identify four main agroenvironments. At 26 of the stations, the elite genotypes of ICARDA were able to outyield the best commercial check. Two stability analysis (Finlay-Wilkinson and additive main effects and multiplicative model wide adaptation index) were used in combination with average grain yield performances to identify the three most stable and widely adapted elite lines, which were given the cross names 'Derazejihan', 'Kundermiki', and 'Bezajihan'. The results gathered here support the usefulness of stability-based indices, the good performances of the ICARDA germplasm, and the need for more coordinated international efforts for this crop.
\end{abstract}

F.M. Bassi and M. Sanchez-Garcia, International Center for the Agriculture Research in the Dry Areas (ICARDA), Rabat, Morocco. Received 1 Nov. 2016. Accepted 25 June 2017. ^Corresponding author (f.bassi@cgiar.org). Assigned to Associate Editor Eric Olson.

Abbreviations: AMMI, additive main effects and multiplicative model; AWAI, additive main effects and multiplicative model wide adaptation index; BLUE, best linear unbiased estimate; CV, coefficient of variation; DtH, days to heading; DtM, days to maturity; GFP, grainfilling period; GxE, genotype $\times$ environment; GY, grain yield; IDYT, International Durum Wheat Yield Trials; IPC, interaction principal component; LR, leaf rust; PCA, principal component analysis; PLH, plant height; PM, powdery mildew; SS, sum square; ST, Septoria tritici blotch; TKW, thousand-kernel weight; TS, tan spot; YR, yellow rust.

$\mathrm{D}$ URUM wheat (Tritcum durum Desf.) is the 10th most important crop in the world, with a global production of $>36 \mathrm{Tg}$ (Ranieri, 2015). Its main use is for industrial transformation to pasta, couscous, and bourghul, foods of the Mediterranean tradition. It is therefore not surprising that the main producers of durum wheat are located in the Mediterranean Basin, with cultivation on 1.6 million ha) in Algeria, 1.5 million ha in Italy, and 0.5 to 0.8 million ha in Morocco, Tunisia, Turkey, Spain, Portugal, and Greece (Le Lamer and Rousselin, 2011; Bonjean et al., 2016; Karabina and Leonardi, 2016). In addition, Egypt, Jordan, and Lebanon recognize the importance of durum wheat and cultivate it in large parts of their arable land (Al-Issa and Samarah, 2006; Karam et al., 2009; El-Areed et al., 2014). This crop has also maintained its importance in West Asia, covering $\sim 0.7$ million ha in Iran, Iraq, and Azerbaijan combined (Adary et al., 2002; Bonjean et al., 2016). Ethiopia is also a major producer of durum wheat, with $\sim 0.6$ million ha of cultivation (Bergh et al., 2012). Canada has recently expanded its area of cultivation to become the biggest producer with $>2.4$ million ha, most of which

Published in Crop Sci. 57:1-12 (2017).

doi: $10.2135 /$ cropsci2016.11.0916

(C) Crop Science Society of America | 5585 Guilford Rd., Madison, WI 53711 USA This is an open access article distributed under the CC BY-NC-ND license (http://creativecommons.org/licenses/by-nc-nd/4.0/). 
is destined for exports (Statistics Canada, 2016). The area of Media Pradesh in India is also experiencing a new raise in cultivation of this crop, with an estimated surface rapidly expanding past 1.5 million ha of land (Nagarajan, 2006). The Sonora desert and other small areas of Mexico also target the production of this crop for the export market on an area of $\sim 0.2$ million ha (Juarez and Wolf, 2015). Finally, some countries are rediscovering this crop, and some pilot tests of adaptation have started. This is for instance the case of the Senegal River, where only 5000 ha of this crop exist today but more can be expected in the near future (Hargreaves et al., 1985; Bassi, 2016).

The International Center for the Agricultural Research in the Dry Areas (ICARDA) is a member of CGIAR, and it has been committed since the early 1980s to improving the global cultivation of durum wheat by means of breeding. Every year, this commitment is performed by freely shipping improved germplasm to partners in countries all over the world. When attempting to simultaneously breed superior durum wheat cultivars for the $>17$ million ha dedicated to this crop, it is critical to understand the complex set of interactions that occur between the genotypes and the environments. It is always challenging to analyze the performance of large numbers of genotypes in multilocation trials.

Several approaches have been proposed to dissect the genotype $\times$ environment $(\mathrm{GxE})$ interaction to better understand it. One of the most used methods to simplify the environment component of the $\mathrm{GxE}$ is to characterize the environments according to the average yield of the genotypes tested in it. Linear regression models can then be fitted with the yield of every genotype at each environment and the average yield of the set of genotypes at each environment. This method, called Finlay-Wilkinson regression (Finlay and Wilkinson 1963), is widely used to characterize the yield response to good environments of a set of genotypes. However, it allows only one type of environment characterization based on average yield. On the other hand, approaches such as the additive main effects and multiplicative model (AMMI) allow characterizing the environment according to more variables (Gauch and Zobel, 1997), such as climatic or pedological data (Sanchez-Garcia et al., 2012), therefore explaining a larger portion of the GxE (for comprehensive review on stability indices, see Malosetti et al., 2013). Additionally, the most explanatory products of the environmental and genotypic sensitivity scores can also be represented in a biplot to simplify discovery. These approaches to the GxE analysis allow characterizing the genotypes as "widely adapted" or as "specifically adapted" to one environment, group of environments, or to specific environmental variables such as climatic variables (e.g., maximum and Gininum temperatures or rainfall). Nevertheless, it is uncommon that a breeder would be interested only in the GxE interaction for genotype selection. Selection indices, incorporating GxE sensitivity proxies, average yield, and/or other variables of interest can be used to characterize, select, and recommend varieties for promotion amongst farmers. Indices combining yield performance with drought tolerance, disease resistance, grain weight, or end-use quality have been proposed (Blum et al., 1989; Branlard et al., 1992; Sharma and Duveiller, 2003). However, validated indices tackling yield performance and adaptation for breeding programs targeting a wide range of different agroecologies are still scarce.

The feedback mechanism developed between ICARDA and its national partners ensures a systematic way to assess these components. The objectives of the present work are (i) to agronomically characterize a set of elite durum wheat lines from the ICARDA international nurseries across 27 environments representative of the main durum wheat growing areas, (ii) to define agroecological groups of environments by clustering according to the response of the set of varieties to the climatic conditions occurring at each site, and (iii) to assess the best selection criteria or indices to easily identify the betteradapted varieties across environments.

\section{MATERIAL AND METHODS Germplasm and Field Sites}

The 38th International Durum Wheat Yield Trials (IDYT) of ICARDA is composed of 18 elite genotypes, five historical checks, and one national check. A complete list of pedigrees is provided in Table 1. The historical checks are: 'Waha' (syn. 'Cham1', 'Sham1', 'Karpasia', 'Maru', 'Celta'), a cultivar released in 10 countries, 'Omrabi5' (syn. 'Cham5', 'Oum rabia', 'Gahar', 'Um Qais', 'Tomouh', 'Firat93') released in 12 countries, 'Azeghar2' (syn. 'Lahn3') released in two countries, 'Icarasha2' (syn. 'Mukiye', 'Ghzael') released in three countries, and 'Miki3' (syn. 'Berdawni', 'Douma41009') released in three countries. In addition, each breeder that receives this set adds the best commercial cultivar available for the specific region under the general name of "national check." This nursery was sent to 64 collaborators in 32 countries for sowing during the season 2014 to 2015 . Among these collaborators, 27 from 18 countries provided feedbacks of their results to ICARDA. A complete list of the responding stations is provided in Table 2. Detailed information concerning the stations agroclimatic conditions was not available, but a discussion of their agroecological similarities is provided in the Results. The best agronomical practices for each region were used, but details were also not provided.

\section{Agronomic Data Collection}

The 24 entries were planted in an $\alpha$ lattice design in two replicates, with six subblocks of size four. Each experimental plot consisted of six rows spaced $0.2 \mathrm{~m}$ apart for $5 \mathrm{~m}$ of length, totaling $6 \mathrm{~m}^{2}$ of planted surface, with a sowing density of $140 \mathrm{~kg}$ $\mathrm{ha}^{-1}$ During the season, the traits listed below were recorded from various stations; the complete list of stations and traits recorded is provided as values in Table 2. For those traits not 
Table 1. The 38th International Durum Wheat Yield Trials of ICARDA.

\begin{tabular}{|c|c|c|}
\hline Cross name & Year of cross & Pedigree \\
\hline Waha & 1980 & Plc/Ruff//Gta/Rtte \\
\hline Omrabi5 & 1982 & Joric69/Hau \\
\hline Azeghar2 & 1992 & 20048Traikia(Mor)/Mrb5//Stj3 \\
\hline Miki3 & 1994 & $\mathrm{Stj} 3 / / \mathrm{Bcr} / \mathrm{Lks} 4$ \\
\hline Icarasha2 & 1999 & Stj3//Bcr/Lks4/3/Ter3 \\
\hline Kundermiki & 2002 & MorlF38//Bcrch1/Kund1149/3/Bicrederaa1/Miki \\
\hline Zagharin2 & 2002 & Icasyr1/3/Gcn//Stj/Mrb3 \\
\hline Ouassara1 & 2003 & Ouasloukos1/5/Azn1/4/BEZAIZSHF//SD19539/Waha/3/Gdr2 \\
\hline Ouassara3 & 2003 & Ouasloukos1/5/Azn1/4/BEZAIZSHF//SD19539/Waha/3/Gdr2 \\
\hline Icamoram7 & 2004 & ICAMORTA0472/Ammar7 \\
\hline Aghramatlas & 2006 & Mgn|3/Ainzen1//Mgn|3/Aghrass2 \\
\hline Bezaghras & 2006 & Ossl1/Stj5/5/Bicrederaa1/4/BEZAIZSHF//SD19539/Waha/3/Stj/Mrb3/6/Mgn|3/Aghrass2 \\
\hline Icacube & 2006 & Mgnl3/Ainzen1//Mgnl3/Ainzen1 \\
\hline Icadezful & 2006 & Geromtel1/IRANYT053//MgnI3/Ainzen1 \\
\hline Icaghram & 2006 & IcamorTA0471//IcamorTA0459/Waha/3/Mgn|3/Ainzen1 \\
\hline Icambel & 2006 & Mrb3/Mna1//Ter1/3/ICAMORTA0459/Ammar7/4/BeltaGY2 \\
\hline Icarukus & 2006 & Maamouri1/5/IcamorTA0462/4/Stj3//Bcr/Lks4/3/lcamor/6/Mgnl3/Ainzen1 \\
\hline Icaverve & 2006 & Azeghar1/4/IcamorTA0462/3/Maamouri3//Vitron/Bidra1/5/Mgnl3/Ainzen1 \\
\hline Margherita & 2006 & Terbol975/Geruftel2 \\
\hline Secondroue & 2006 & Stj3//Bcr/Lks4/3/Ter3/4/Bcr/Gro1//Mgnl1 \\
\hline Bezajihan & 2007 & Ossl1/Stj5/5/Bicrederaa1/4/BezaizSHF//SD19539/Waha/3/Stj/Mrb3/6/lcajihan12 \\
\hline Derazejihan & 2007 & Bicrederaa1/Azeghar2//Icajihan25 \\
\hline Icavert & 2007 & Ter1/3/Stj3//Bcr/Lks4/4/Aghrass1/3/Mrf1//Mrb16/Ru \\
\hline National check $\dagger$ & Various & Various \\
\hline
\end{tabular}

† One entry selected by each station as the best commercial cultivar for the location.

listed in Table 2, a list of locations recording these is provided below. Days to heading (DtH) was the number of days from sowing to the moment when $50 \%$ of the plot reaches Zadoks stage 59 (Zadoks et al., 1974). Days to maturity (DtM) was the number of days from sowing to the moment when $50 \%$ of the plot reaches Zadoks stage 89 (Zadoks et al., 1974). Grain-filling period (GFP) was recorded as the difference in days between DtH and DtM. Plant height (PLH) was the distance in centimeters from soil level to the tip of the spikes, excluding the awns, of randomly selected plants within the plot. Once all plots reached maturity, the following traits were measured and the stations from which these were obtained are reported in Table 2 or are listed for each trait. Grain yield (GY) was recorded by threshing the central four rows of the plot for a total harvested surface of $4 \mathrm{~m}^{2}$. The grains were then weighted and the final value expressed as kilograms per hectare. This value was recorded at all 27 locations. For thousand-kernel weight (TKW), a total of 1000 grains were counted and then weighted on a precision scale; their weight is expressed in grams.

\section{Wheat Diseases Data Collection}

Rust diseases were recorded following the modified Cobb's scale (Peterson et al., 1948), whereas blasts were recorded using the Saari-Prescott double-digit scale (Saari and Prescott, 1975). In this manuscript, the disease response is presented as "susceptibility to diseases," which is expressed as a qualitative result with the "susceptible" score given if, at any of the stations, the genotype showed a disease response equal to or worse than the average for any of the two replicates. The specific diseases and the stations where these were scored are: powdery mildew (PM, caused by Erysiphales spp.), which was recorded in Baky and
Sids stations; Septoria tritici blotch (ST, caused by Zymoseptoria tritici), which was recorded in Foggia and Sidi el Aidi; tan spot (TS, caused by Pyrenophora tritici-repentis), which was recorded in Marchouch, Sidi el Aidi, and in a disease nursery located in Rabat (Morocco); yellow rust (YR, caused by Puccinia striiformis f. sp. tritici), which was recorded in Elvas, Marchouch, and Sids; and leaf rust (LR, caused by Puccinia triticina), which was recorded in Foggia, Marchouch, Sidi el Aidi, Sids, and in a disease nursery located in Rabat (Morocco).

\section{Data Analysis}

Genstat (Payne et al., 2006) was used to conduct the ANOVA across environments for an $\alpha$ lattice design, with genotypes and environments as fixed factors. Best linear unbiased estimates (BLUEs) were derived and standard error of the differences of the means used to determine significant differences. Broad sense-heritability was calculated as follows:

$$
H^{2}=\frac{\delta_{\mathrm{G}}}{\delta_{\mathrm{G}}+\frac{\delta_{\mathrm{GxE}}}{n_{\mathrm{E}}}+\frac{\delta_{\mathrm{e}}}{n_{\mathrm{E}} n_{\mathrm{r}}}}
$$

where $\delta_{\mathrm{G}}$ is obtained as the sum square (SS) value for genotype, $\delta_{\mathrm{GxE}}$ is the $\mathrm{SS}$ of the $\mathrm{GxE}$ interaction, $n_{\mathrm{E}}$ is the number of environments, $\delta_{e}$ is the SS of the error, and $n_{\mathrm{r}}$ is the number of replicates. The freely available 64-bit version of the statistical package $\mathrm{R}$ version 3.3.0 ( $\mathrm{R}$ Development Core Team, 2011) was used for allotherstatistical analysis. The java script Genotype $\times$ Environment Analysis with R (GEA-R) (Pacheco et al., 2016) was used to conduct the AMMI model (Zobel et al., 1988) and the principal component analysis (PCA) for the 
Table 2. Results for major traits at each of the 27 locations and across all locations.

\begin{tabular}{|c|c|c|c|c|c|c|c|c|c|c|c|c|c|c|c|}
\hline \multirow[b]{3}{*}{ Station } & \multirow[b]{3}{*}{ Country } & \multirow[b]{3}{*}{ Groupł } & \multirow[b]{3}{*}{ Best line§ } & \multicolumn{12}{|c|}{ Trait $†$} \\
\hline & & & & \multicolumn{2}{|c|}{ GY } & \multicolumn{2}{|c|}{ DtH } & \multicolumn{2}{|c|}{ DtM } & \multicolumn{2}{|c|}{ GFP } & \multicolumn{2}{|c|}{ PLH } & \multicolumn{2}{|c|}{ TKW } \\
\hline & & & & Avg. & $\mathrm{CV}$ & Avg. & $\mathrm{CV}$ & Avg. & $\mathrm{CV}$ & Avg. & CV & Avg. & $\mathrm{CV}$ & Avg. & $\mathrm{CV}$ \\
\hline & & & & $-\mathrm{kgr}$ & $a^{-1}-$ & & 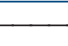 & $-c$ & 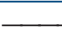 & 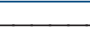 & - & $-\mathrm{Cl}$ & $1-$ & $-c$ & 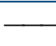 \\
\hline Foggia & Italy & 1 & Ouassara3 & 5,538 & 9.1 & 136 & 0.2 & & & & & 90 & 0.9 & & \\
\hline Debre Zeit & Ethiopia & 2 & Icaghram & 4,269 & 14.1 & 60 & 0.9 & 102 & 1.3 & 41 & 2.9 & 79 & 4.9 & 32 & 8.4 \\
\hline Gachsaran & Iran & 2 & Miki3 & 3,275 & 11.2 & 90 & 1.7 & 144 & 0.5 & 54 & 3.5 & 73 & 2.2 & 30 & 5.3 \\
\hline Guelma & Algeria & 2 & Icambel & 4,991 & 15.9 & 152 & 0.2 & 208 & 0.8 & 57 & 2.8 & 76 & 3.2 & na & \\
\hline Maru & Jordan & 2 & Margherita & 3,462 & 10.9 & 104 & 1.0 & 148 & 0.5 & 44 & 2.7 & 92 & 2.8 & 44 & 3.1 \\
\hline El Kef & Tunisia & 2 & Ouassara3 & 2,046 & 10.8 & 117 & 1.1 & na & & na & & 97 & 2.0 & na & \\
\hline Erbil & Iraq & 2 & Margherita & 2,286 & 14.2 & na & & na & & na & & na & & 32 & 0.9 \\
\hline Amlah & India & 3 & Margherita & 3,579 & 14.6 & 77 & 1.8 & 137 & 0.9 & 60 & 3.0 & 87 & 1.7 & na & \\
\hline Eleftere & Greece & 3 & Icarasha2 & 6,131 & 6.5 & 144 & 1.0 & na & & na & & 72 & 3.4 & na & \\
\hline Marchouch & Morocco & 3 & Icarukus & 6,040 & 7.1 & 118 & 1.7 & 172 & 0.6 & 55 & 4.1 & 92 & 3.1 & 49 & 3.3 \\
\hline Oued Smar & Algeria & 3 & Ouassara3 & 3,913 & 10.1 & 104 & 0.3 & 149 & 1.2 & 45 & 3.9 & 97 & 4.9 & na & \\
\hline Sids & Egypt & 3 & Icaverve & 11,555 & 4.7 & 92 & 1.6 & 144 & 0.5 & 51 & 3.6 & 107 & 3.2 & na & \\
\hline Fanaye & Senegal & 3 & Zagharin2 & 3,139 & 14.3 & 53 & 1.8 & 86 & 4.3 & 34 & 10.7 & 76 & 4.1 & na & \\
\hline Obregon drip & Mexico & 3 & Margherita & 2,378 & 4.8 & 65 & 0.9 & na & & na & & 66 & 4.2 & 46 & 2.6 \\
\hline Ecija & Spain & 3 & Margherita & 5,680 & 4.0 & 131 & 0.5 & na & & na & & na & & na & \\
\hline Swift Current & Canada & 3 & Kundermiki & 1,480 & 11.1 & na & & na & & na & & na & & na & \\
\hline Moghan & Iran & 3 & Azeghar2 & 4,208 & 6.3 & na & & na & & na & & na & & na & \\
\hline Elvas & Portugal & 4 & Nat. check & 4,498 & 11.1 & 95 & 0.5 & 156 & 0.2 & 61 & 0.6 & 84 & 2.7 & 48 & 0.9 \\
\hline Sidi El Aidi & Morocco & 4 & Icavert & 3,674 & 15.9 & 120 & 0.8 & 170 & 0.7 & 49 & 2.4 & 92 & 5.0 & na & \\
\hline Tel Amara & Lebanon & 4 & Miki3 & 2,421 & 9.0 & 137 & 0.9 & 170 & 0.6 & 32 & 2.2 & 61 & 0.9 & na & \\
\hline Mushager & Jordan & 4 & Icarasha2 & 2,575 & 15.6 & 117 & 0.8 & 158 & 0.6 & 41 & 3.4 & 93 & 6.3 & na & \\
\hline Baky & Azerbaijan & 4 & Ouassara1 & 4,154 & 15.8 & 123 & 0.1 & na & & na & & 91 & 1.1 & na & \\
\hline El Khroub & Algeria & 4 & Icarukus & 3,136 & 16.8 & 130 & 0.7 & na & & na & & 54 & 3.6 & na & \\
\hline Obregon full & Mexico & 4 & Margherita & 5,394 & 7.9 & 70 & 2.0 & na & & na & & 88 & 3.3 & 46 & 7.0 \\
\hline Terbol & Lebanon & 4 & Margherita & 7,258 & 7.1 & 135 & 0.8 & 186 & 0.5 & 51 & 3.2 & 86 & 2.4 & 52 & 3.3 \\
\hline Bousselham & Algeria & 4 & Icamoram7 & 4,277 & 8.3 & na & & na & & na & & na & & na & \\
\hline AREC & Lebanon & 4 & Ouassara1 & 2,908 & 9.1 & 147 & 0.9 & 184 & 0.9 & 38 & 2.4 & na & & na & \\
\hline Across locations & & & Ouassara3 & 4,232 & 10.3 & 107 & 1.1 & 162 & 0.7 & 47 & 3.7 & 83 & 3.5 & 42 & 8.4 \\
\hline
\end{tabular}

† GY, grain yield; DtH, days to heading; DtM, days to maturity; GFP, grain-filling period; PLH, plant height; TKW, thousand-kernel weight; CV, coefficient of variation; na, data not available.

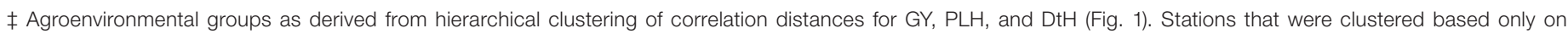
similarities for GY are indicated with a bolded group number (Fig. 3).

$\S$ Top-yielding genotype at each location.

genotype main effects and GxE model or genotype + genotype X environment (Perkins, 1972; Yan et al., 2000). Hierarchical clustering among locations was determined by applying the $\mathrm{R}$ based package "hclust" to a matrix of correlations among PLH, DtH, and GY at 21 locations (Fig. 1). Excel was used to derive two yield stability indices for GY only: the Finlay-Wilkinson regression line (Finlay and Wilkinson, 1963) was estimated as described in Malosetti et al. (2013) by using the "linest" function for the regression between the GY value of each genotype at each station against the average yield of each station. The slope of the regression line $\left(b^{\prime}\right)$ was derived. The second yield stability value was derived from the AMMI model as suggested by Sneller et al. (1997) following the method described in Sabaghnia et al. (2008). This was named the AMMI wide adaptation index (AWAI), and it was derived from summing for each genotype the absolute value of each interaction principal component (IPC) multiplied by the fraction of SS explained by each principal component as derived from the Gollobs test (Gollob, 1968). The analysis was conducted using only IPCs explaining $>10 \%$ of the GxE-in this case, the first three IPCs, which together explained $42.3 \%$ of the total $\mathrm{GxE}$ variance. Low values of AWAI are indicative of genotypes that are close to the axis of the AMMI graph and are therefore widely adapted. The number of "victories" was derived as the number of sites at which each genotype was the highest yielder. The ranking score was derived from selecting the genotypes above the intersection of lines traced at the position of the best 10th entry for each axis (Fig. 2). Genotypes in this intersection were therefore among the top 10 for multiple scores. A cumulative qualitative score was given, with the value "Top" assigned to genotypes that were within the intersection for yield across environments and both stability indices ( $b^{\prime}$ and AWAI). A "good" score was given to those entries that were at least above the intersection for GY and at least one of the two stability indices. "Average" scores were those genotypes that were among the top 10 for at least one of the axis, and "worst" was reserved for those entries that performed poorly for both indices. 


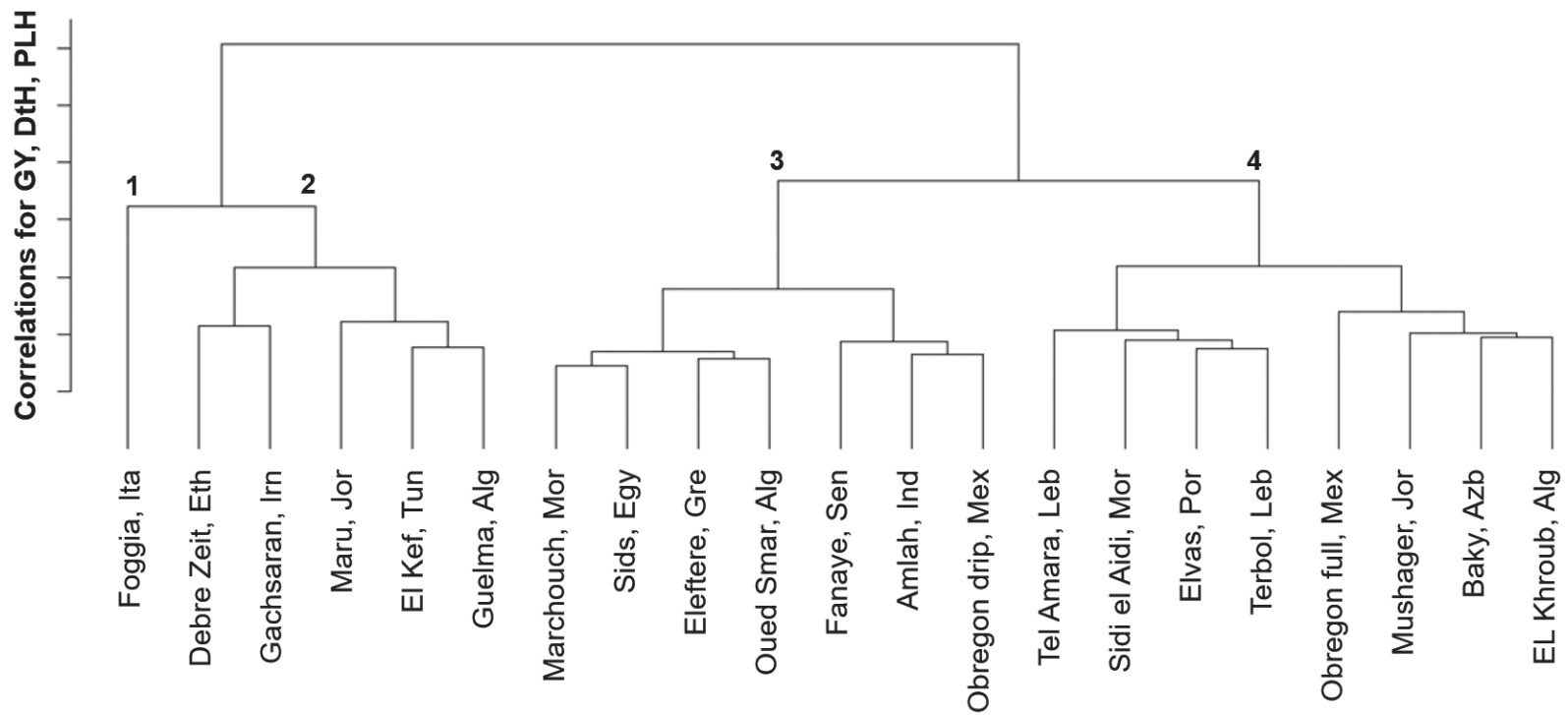

Fig 1. Multiple-trait analysis of similarities among environments based on their reciprocal correlations for grain yield (GY), days to heading $(\mathrm{DtH})$, and plant height (PLH). The length of each arm of the dendogram is proportional to the similarity between stations, with shorter arms indicating tighter similarities. Four major agroenvironmental groups are identified by this analysis, and their numbers are presented above the differentiating node.

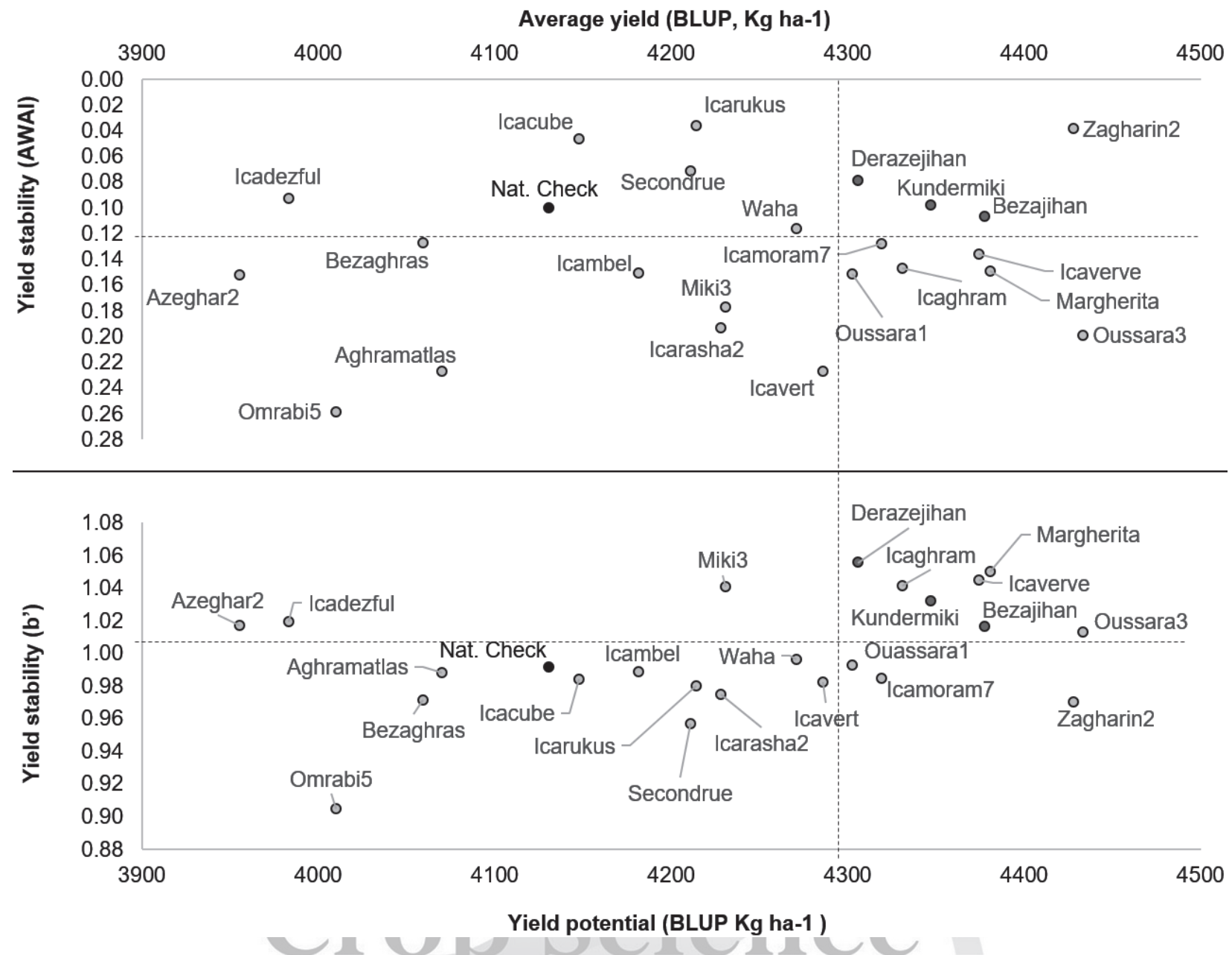

Fig 2. Stability indices selection based on additive main effects and multiplicative model wide adaptation index (AWAI) above and Finlay-Wilkinson angle of the regression curve $\left(b^{\prime}\right)$ below, against yield potential expressed as the best linear unbiased prediction (BLUP) of grain yield ( $\left.\mathrm{kg} \mathrm{ha}^{-1}\right)$ across 27 locations. The dashed lines were traced at the/position of the/10th best entry for each axis. The cross-identification name of each entry is reported next to theír biplot position. The entries in the top right corner of each graph can be considered both stable and top yielding. A dark grey circle is used to identify top-performing genotypes in both graphs. The value for the national check is reported as a black dot. 


\section{RESULTS}

The vast majority of the variance of the ANOVA was explained by the environment factor, which explained from 76 to $>99 \%$ of the total variance for TKW and DtM, respectively. In the case of GY, the effect of the genotype was limited to $1 \%$, and the GxE effect reached 9.6\%.

The most heritable trait was DtH with a value of 0.9, and the least heritable were GY and DtM with 0.6 (Table 3). Correlations across all environments (Table 4) showed interactions between DtH, GFP, and DtM, with late-flowering genotypes typically having shorter periods to fill the grains $(r=-0.93, p<0.01)$ and also maturing later $(r=0.64, p<0.01)$. Further, late-maturing genotypes had the tendency of being taller $(r=0.68, p<0.01)$. Interestingly, genotypes with longer GFP usually had larger TKW $(r=0.54, p<0.01)$, but this extended GFP had a negative effect on the GY $(r=-0.67, p<0.01)$, which was also negatively affected by late maturity $(r=-0.67$, $p<0.01)$. Plant height, $\mathrm{DtH}$, and TKW had no significant effects on GY.

\section{Performances across 27 Experimental Stations}

A total of 27 experimental stations located in 18 countries were used for this analysis. In Table 2, we treported the average performances at each station for six major traits. The top-yielding environment was Sids in Egypt with an average of $11,555 \mathrm{~kg} \mathrm{ha}^{-1}$ obtained under full-gravity irrigation and mild infection of PM, LR, and YR. The lowest-yielding station was Swift Current in Canada with an average of $1480 \mathrm{~kg} \mathrm{ha}^{-1}$ obtained with summer planting and severe terminal drought. The average GY overall was $4232 \mathrm{~kg} \mathrm{ha}^{-1}$. The four major environments of CGIAR centers (ICARDA and CIMMYT) performed at 2378, 5394, 6040, and $7258 \mathrm{~kg} \mathrm{ha}^{-1}$ for Obregon reduced drip irrigation, Obregon full irrigation, Marchouch, and Terbol, respectively. The timespan to reach heading $(\mathrm{DtH})$ is a good indicator of the temperatures occurring at the various stations, with the shortest cycle recorded in Fanaye (53 d) along the Senegal river, where daily temperatures
Table 4. Correlation analysis for all traits across nine locations.

\begin{tabular}{llllll}
\hline & \multicolumn{5}{c}{ Trait $\dagger$} \\
\cline { 2 - 5 } Trait & GY & PLH & GFP & DtM & DtH \\
\hline PLH & -0.08 & & & & \\
GFP & $-0.67^{\star *}$ & 0.16 & & & \\
DtM & $-0.67^{\star *}$ & $0.68^{\star *}$ & -0.39 & & \\
DtH & 0.26 & 0.17 & $-0.93^{\star \star}$ & $0.64^{\star \star}$ & \\
TKW & -0.10 & 0.00 & $0.54^{\star}$ & 0.34 & -0.26 \\
\hline
\end{tabular}

** Significant at the 0.01 probability level.

† GY, grain yield; DtH, days to heading; DtM, days to maturity; GFP, grain-filling period; PLH, plant height; TKW, thousand-kernel weight.

$>30^{\circ} \mathrm{C}$ are common throughout the growing cycle, and the longest in Guelma (152 d), on the cold high plateaus of Algeria. Time to reach maturity (DtM) is also determined by the combination of water availability and temperatures and followed the same pattern as DtH with the shortest in Fanaye after $86 \mathrm{~d}$ and the longest in Guelma after $208 \mathrm{~d}$. However, the GFP showed slightly different response due to the specific conditions that occurred at the various stations between the time of heading and maturity, with Tel Amara in Lebanon being the shortest (32 d) and Elvas in Portugal the longest $(61 \mathrm{~d})$. The ability of the genotype to grow is highly related to water abundance, and the station with highest PLH was the one with the most abundant irrigation, Sids in Egypt. The smallest PLH was measured at El Khroub in Algeria, where severe early and terminal droughts occurred. Finally, TKW was recorded at only nine locations; among these, the highest value was $52 \mathrm{~g}$ and the lowest $30 \mathrm{~g}$ for Terbol in Lebanon and Gachsaran in Iran, respectively. In terms of experimental error, the best station was Ecija in Spain, which is under the administration of a private company (AgroVegetal) and reached 4.0\% coefficient of variance (CV) for GY. The highest CV was registered in El Khroub, Algeria, under very severe drought conditions, with a value of $16.8 \%$. The experiment overall had a CV of $10.3 \%$ for GY, which is deemed acceptable considering the large international effort. Conversely, the four major stations of CGIAR centers (ICARDA and CIMMYT) performed at CVs of 4.8, 7.9, 7.1, and 7.1\% for

Table 3. Sum of squares of the fixed terms of the model across locations for different traits.

\begin{tabular}{|c|c|c|c|c|c|c|}
\hline \multirow[b]{2}{*}{ Source of variation } & \multicolumn{6}{|c|}{ Trait† } \\
\hline & $\mathrm{GY}\left(\times 10^{7}\right)$ & DtH $\left(\times 10^{3}\right)$ & $\operatorname{DtM}\left(x \times 10^{3}\right)$ & GFP $\left(\times 10^{3}\right)$ & PLH $\left(\times 10^{3}\right)$ & $\operatorname{TKW}\left(\times 10^{3}\right)$ \\
\hline Genotype (G) & $5.76^{\star \star \star}$ & $1.6^{\star \star \star}$ & $0.4^{\star \star \star}$ & $1.3^{\star \star \star}$ & $8.2^{\star \star \star}$ & $2.5^{\star \star \star}$ \\
\hline Ratio total variance (\%) & 1.0 & 0.2 & 0.1 & 2.0 & 4.0 & 7.0 \\
\hline$G \times E$ & $57.5^{\star \star \star}$ & $3.3^{\star \star \star}$ & $4.6^{\star \star \star}$ & $5.8^{\star \star \star}$ & $26.0^{\star \star \star}$ & $5.2^{\star \star \star}$ \\
\hline Ratio total variance (\%) & 9.6 & 0.4 & 0.7 & 8.9 & 12.7 & 14.6 \\
\hline Environment (E) & $516.3^{\star \star \star}$ & & & $56.5^{\text {*** }}$ & $164.2^{\star \star \star}$ & $27.1^{\star \star \star}$ \\
\hline Ratio total variance & 86.4 & 3 & 99.1 & 86.7 & 80.4 & 76.0 \\
\hline Heritability & 0.65 & 0.90 & 0.62 & 0.68 & 0.84 & 0.74 \\
\hline SED $\ddagger$ & 91.6 & 0.3 & 0.4 & 0.5 & 1.5 & 0.6 \\
\hline
\end{tabular}

*** Significant at the 0.001 probability level.

SOCIEIIOHAIVERICA

† GY, grain yield; DtH, days to heading; DtM, days to maturity; GFP, grain-filling period; PLH, plant height; TKW, thousand-kernel weight.

$\ddagger$ SED, Standard error of the differences of the means. 
Obregon reduced drip irrigation, Obregon full irrigation, Marchouch, and Terbol, respectively.

\section{Agroenvironmental Groups}

The agroecological conditions remain unknown for most of the stations. To determine their similarities, the performances of the genotypes at 21 stations for GY, DtH, and PLH were used as proxy for overall conditions, such as temperatures before flowering and water abundance. A correlation "all against all" revealed interactions among stations for the traits. Hirerachical clustering was used to merge the results for the three traits into one overall score, using as distance matrix the correlation values. This analysis revealed four major agroecological groups (Fig. 1). The station of Foggia (Italy) was the most dissimilar from all and created a group on its own: Group 1. The environmental conditions at Debre Zeit (Ethiopia), Gachsaran (Iran), Maru (Jordan), El Kef (Tunisia), and Guelma (Algeria) caused similar responses in the genotypes for the three traits and therefore were grouped into one cluster: Group 2. Group 3 was composed of Marchouch (Morocco), Sids (Egypt), Eleftere (Greece), Oued Smar (Algeria), Fanaye (Senegal), Amlah (India), and Obregon partial irrigation by drip (Mexico). Group 4 clustered Tel Amara (Lebanon), Sidi el Aidi (Morocco), Elvas (Portugal), Terbol (Lebanon), Obregon full irrigation (Mexico), Mushager (Jordan), Baky (Azerbaijan), and El Khroub (Algeria). At the remaining six stations, DtH and PLH were not recorded. To merge these into the agroenvironmental groups, a PCA model was performed for GY alone (Fig. 3). The stations were then incorporated into groups based on their similarities to other assigned locations. On this basis, Erbil (Iraq) was assigned to Group 2; Moghan (Iran), Swift Current (Canada), and Ecija (Spain) to Group 3; and Bousselham (Algeria) and AREC (Lebanon) to Group 4 (Table 2). Considering these additions, Groups 3 and 4 were as the largest with 10 stations each, followed by Group 2 with six stations and Group 1 with just one station.

\section{Performances of Genotypes}

The average highest-yielding genotype across all locations was 'Ouassara3', followed by 'Zagharin2' with 4434 and $4428 \mathrm{~kg} \mathrm{ha}^{-1}$, respectively (Fig. 2). The overall top yielder was 'Icaverve' at Sids station (Egypt) with 12,099 $\mathrm{kg} \mathrm{ha}^{-1}$, whereas the lowest yielding was 'Bezaghras' in AREC (Lebanon) with $1012 \mathrm{~kg} \mathrm{ha}^{-1}$. All genotypes completed their growing cycle at all stations, including the heat-affected Fanaye (Senegal) and the summer-planted Swift Current (Canada), suggesting no vernalization requirements and no photoperiod sensitivity among the genotypes. Days to heading across all locations ranged from $109 \mathrm{~d}$ for 'Icacube' to $105 \mathrm{~d}$ for several entries (Table 5). Also, DtM and GFP varied mildly when considering all

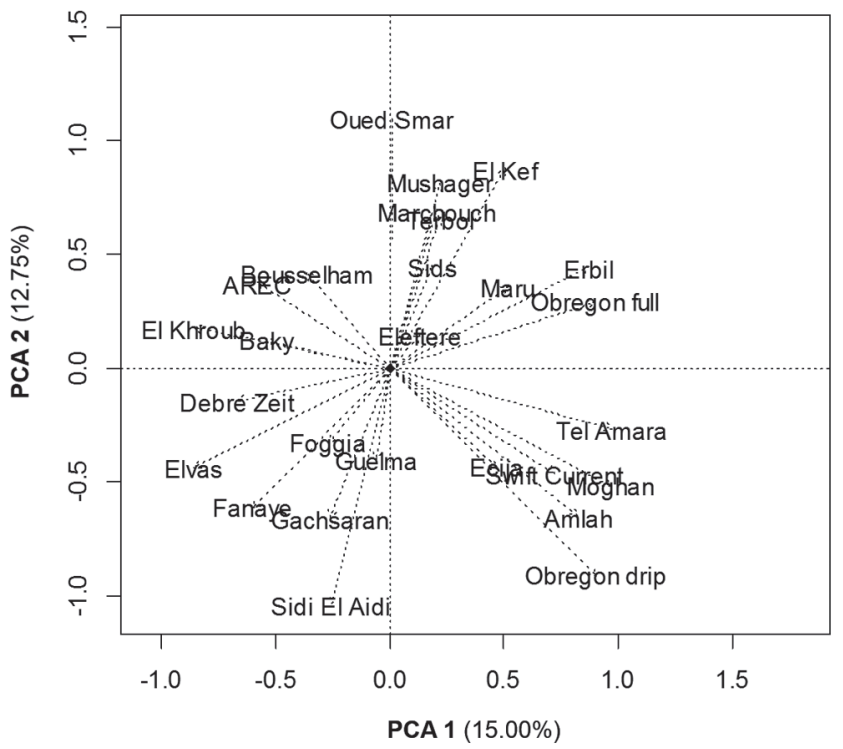

Fig 3. Single-trait analysis of similarities between locations using a genotype + genotype $\times$ environment (GGE) model generated on the basis of grain yield performances. PCA, principal component analysis.

locations, with a range of $\pm 3 \mathrm{~d}$. In terms of PLH, Omrabi 5 was consistently the tallest genotype, with $90 \mathrm{~cm}$ across all locations, whereas 'Icamoram7' was the shortest at $78 \mathrm{~cm}$. The largest grains were produced by 'Derazejihan' with a BLUE for TKW of $45 \mathrm{~g}$ across nine locations, and the smallest by 'Aghramatlas' with $38 \mathrm{~g}$ (Table 5). The disease susceptibility varied for all genotypes, with the overall most resistant being Icaverve, only susceptible to TS, whereas Omrabi5 and Icamoram7 were susceptible to all assessed diseases. Across all locations, the most virulent disease was ST with 21 genotypes susceptible to it, followed by TS with 19 genotypes, PM with 18, LR with 17, and finally YR with just two genotypes (Table 5).

Among the 27 locations assessed, at all but Elvas (Portugal), an ICARDA genotype outyielded the national check (Table 2). In particular, 'Margherita' was the bestyielding entry in seven of the 27 locations. These seven locations belonged to the agroenvironmental Groups 2, 3, and 4 (Table 2). Ouassara3 was the best in three environments (Table 5) belonging to Groups 1, 2, and 3. Overall, nine of the 24 entries were never able to outyield all others at any of the environments tested. Among these, two were old checks (Waha and Omrabi5). Instead, the three modern checks (Azeghar2, Miki3, and Icarasha2) considered together succeeded in outperforming all others at five of the stations.

\section{Selection Indices}

Two stability analyses were performed for GY across all locations (Fig./2). The first/analysis of stability was conducted using a wide adaptation index derived from the first three IPC of the AMMI model (AWAI), which measures 
Table 5. Performances of the 38th international durum yield trials for various traits.

\begin{tabular}{|c|c|c|c|c|c|c|c|c|}
\hline \multirow[b]{2}{*}{ Cultivar } & \multirow[b]{2}{*}{ Ranking $\ddagger$} & \multirow[b]{2}{*}{ Victories§ } & \multicolumn{5}{|c|}{ BLUE† } & \multirow[b]{2}{*}{ Disease susceptibility } \\
\hline & & & DtH & DtM & GFP & PLH & TKW & \\
\hline Derazejihan & Top & 0 & 107 & 162 & 47 & 86 & 45 & ST, TS \\
\hline Kundermiki & Top & 1 & 106 & 162 & 48 & 81 & 39 & ST, TS \\
\hline Bezajihan & Top & 0 & 107 & 162 & 49 & 86 & 43 & PM, ST, LR, TS \\
\hline Icaghram & Good & 1 & 108 & 163 & 47 & 83 & 42 & ST, TS \\
\hline Icaverve & Good & 1 & 106 & 163 & 48 & 85 & 43 & TS \\
\hline Ouassara3 & Good & 3 & 105 & 161 & 48 & 83 & 40 & PM, LR, TS \\
\hline Margherita & Good & 7 & 105 & 162 & 48 & 83 & 44 & ST, TS \\
\hline Zagharin2 & Good & 1 & 105 & 162 & 48 & 84 & 45 & PM, ST, LR, TS \\
\hline Waha & Average & 0 & 107 & 162 & 46 & 83 & 40 & PM, ST, LR \\
\hline Ouassara1 & Average & 2 & 108 & 162 & 46 & 84 & 42 & PM, ST, LR, TS \\
\hline Icacube & Average & 0 & 109 & 163 & 46 & 82 & 42 & PM, ST, LR, TS \\
\hline Icamoram7 & Average & 1 & 107 & 161 & 46 & 78 & 40 & PM, ST, LR, YR, TS \\
\hline Icarukus & Average & 2 & 107 & 162 & 47 & 85 & 44 & PM, ST, LR \\
\hline Miki3 & Average & 2 & 107 & 162 & 47 & 84 & 43 & PM, ST, LR, TS \\
\hline Icarasha2 & Average & 2 & 105 & 162 & 48 & 86 & 42 & PM, ST, LR, TS \\
\hline Icadezful & Average & 0 & 105 & 163 & 48 & 83 & 42 & PM, ST, LR, TS \\
\hline Secondroue & Average & 0 & 105 & 162 & 49 & 85 & 41 & PM, ST, LR, TS \\
\hline Azeghar2 & Average & 1 & 107 & 162 & 47 & 82 & 44 & PM, ST, LR \\
\hline Icavert & Average & 1 & 107 & 163 & 47 & 81 & 42 & PM, ST, TS \\
\hline Icambel & Average & 1 & 107 & 163 & 47 & 80 & 42 & PM, ST, LR, TS \\
\hline Aghramatlas & Worst & 0 & 108 & 162 & 46 & 81 & 38 & PM, ST, LR \\
\hline Omrabi5 & Worst & 0 & 107 & 163 & 48 & 90 & 40 & PM, ST, LR, YR, TS \\
\hline Bezaghras & Worst & 0 & 105 & 162 & 48 & 82 & 42 & PM, ST, LR, TS \\
\hline SED & & & 0.26 & 0.42 & 0.51 & 1.50 & 0.64 & \\
\hline
\end{tabular}

† BLUE, best linear unbiased estimate across locations; DtH, days to heading; DtM, days to maturity; GFP, grain-filling period; PLH, plant height; TKW, thousand-kernel weight. The number of environments used for the analysis is as follows: $\mathrm{DtH}=16$ environments, $\mathrm{DtM}=10$ environments, GFP $=10$ environments, PLH $=21$ environments, TKW $=9$ environments.

‡ Ranking performances based on the combination of two selection indices as shown in Fig. 2.

$\S$ Number of locations at which the specific genotype was the best yielding

I The varieties were considered susceptible to a given disease if at any of the stations the genotype showed a disease response equal or worse than the mean for any of the two replicates. The number of environments used for the analysis is as follows: powdery mildew $(P M)=2$ environments, yellow rust (YR) $=3$ environments, Septoria tritici blotch $(\mathrm{ST})=2$ environments, leaf rust $(\mathrm{LR})=5$ environments, tan spot $(\mathrm{TS})=4$ environments.

the ability to perform steadily at all environments. Low scores are attributed to the most widely adapted genotypes, with values $<0.2$ considered as acceptable (Sneller et al., 1997; Sabaghnia et al., 2008). The highest score was attributed to Omrabi5 with 0.26 , whereas the most stable entries were 'Icarukus' and Zagharin2 with 0.04. The average performance of all genotypes was 0.13 , with 21 entries having scores $<0.2$. Interestingly, the score for the national check, which is represented by the best commercially available genotype at each location and therefore by the cultivar known to be adapted to the specific environment, was 0.1 . A total of six elites scored better than the national check.

The second analysis of stability used the angle of the regression line of the Finlay-Wilkinson method $\left(b^{\prime}\right)$, which determines the ability of each genotype to adapt to improving environmental conditions, also defined as "dynamic stability." In this case, scores close to 1 determine the most dynamically stable genotype, and scores $>0.97$ are deemed acceptable (Malosetti et al., 2013). Twenty-tyo of the entries scored 0.97 or above. Simultaneously, high $b^{\prime}$ scores are indicative of genotypes that respond to improving conditions better than the average increase in performances. These genotypes were deemed the most interesting when combined with information on the average yields (Fig. 2). The lowest score was recorded for Omrabi5 with 0.9 and the highest for Derazejihan with 1.05.

Since high stability can be caused by average low yields, a selection index was derived by plotting the two methods presented above against the BLUE for GY across all environments (Fig. 2). The top 10 entries for the BLUE of GY and the top 10 for stability measures were selected. The intersection of these two selection criteria revealed four elites for the AWAI method: Zagharin2, Derazejihan, 'Kundermiki', and 'Bezajihan'. For the $b^{\prime}$ method, seven elites were instead selected: 'Icaghram', Icaverve, Margherita, Ouassara3, Derazejihan, Kundermiki, and Bezajihan. Combining the two selection indices, three elites were selected by both (Derazejihan, Kundermiki, and Bezajihan) and are presented as the "top" in Table 5, whereas five were selected by only one wethod and are indicated as "good". Among the top, only Kundermiki was recorded as a best yielder in one environment (Swift Current, Canada), whereas for the 
good, a total of 16 victories were recorded. In the opposite sense, three entries were located in the bottom left corner by both indices and were identified as the "worst" in Table 5: Aghramatals, Omrabi5, and Bezaghras.

\section{DISCUSSION}

Phenotypic information of 24 durum wheat genotypes was collected from 27 stations located in 18 different countries. This represents, to the best of our knowledge, the most globally spread multilocation yield trial of durum wheat published to date. The genotypic component of the variance explained only a small portion of the total source of variation for all traits, indicating that the environments were more different from each other than the genotypes. These results are typical of multilocation experiments where the environments are highly diverse (e.g., Voltas et al., 2005). The heritability of both GY and DtM was 0.6 and for GFP and TKW reached 0.7, whereas it was higher for DtH and PLH. The lower score of GY is probably due to the multiple genes controlling this trait and the interactions that each gene has with the environment (Giunta et al., 1993; De Vita et al., 2010; Subira et al., 2015). The case of low heritability for DtM might be explained by the same reasons of GY, with a particular importance attributed to the effect of high temperatures and low water availability that occur at the end of the cycle in Mediterranean-type climates (Salem, 1989). Thousand-grain weight, DtH, and PLH are simpler traits whose main effects are controlled by a limited number of genes, a fact that in turn would explain their higher heritabilities (De Vita et al., 2010; Subira et al., 2015). In regard to GFP, this trait was calculated as a subtraction between the values of DtM and DtH. It is therefore expectable that its heritability locates in between the two traits, with its initial flowering stage controlled by simple Mendelian gene effects like DtH, and its final stages more strongly influenced by temperatures and water availability like DtM (Kumari et al., 2013).

Correlation analysis of six traits at nine locations revealed that early-flowering and late-maturing genotypes tend to have longer GFP, larger TKW, and altogether result in lower yields. No other significant effect on GY could be identified. This is against previously reported work (Wiegand and Cuellar, 1980; del Moral et al., 2002; Álvaro et al., 2008; Maccaferri et al., 2008) that suggested that earliness and TKW would have a positive effect on GY in Mediterranean environments. Two explanations could be devised for the results reported here: (i) the environments used in this study are not all of Mediterranean types, with records also coming from Canada, Senegal, India, irrigated Egypt, and Mexico; and (ii) among the small set of genotypes used here, the highest yielding were also heat or drought tolerant per se and did not need earliness as a way to "escape" terminal stresses. It is certainly true that not all environments used in this study are of traditional Mediterranean type. Nevertheless, the stations in Senegal, India, Egypt, and Mexico exposed the germplasm to high terminal temperatures. Also, the station of Swift Current (Canada) and of Amlah (India) experienced severe terminal droughts in the season 2014 to 2015, when the experiment was conducted. Therefore, the explanation of the lack of correlation between DtH and GY can only be partially attributed to the specific agroenvironmental conditions.

Instead, it can be seen from Table 5 that several genotypes were the best performing in one or more station, even though these flowered on average $3 \mathrm{~d}$ later than the earlier lines. This was the case of 'Ouassara1' and Icaghram. However, two of the best-performing elites (Margherita and Oussara3) are among the earliest genotypes. The results of the present study showed that there was no absolute winner genotype. This could be a result of the large environmental differences between locations that would favor different performance strategies. The result of no correlation between GY and TKW is possibly more surprising, as it is in clear contrast with the finding of Marti and Slafer (2014), who suggested that most of the genetic gain for GY in durum wheat was achieved by breeding for larger kernels. However, other studies have shown grains per spike and spikes per square meter as main factors for increasing durum wheat productivity in Mediterranean environments (Royo et al., 2007; De Vita et al., 2010). Among the tested environments, a strong interaction existed between GFP and TKW, suggesting that genotypes capable of extending the time between heading and maturity are rewarded by larger grains (Isidro et al., 2011). Simply, the top-yielding genotypes studied here did not appear to use this strategy for ensuring good performances. In turn, this provides an ideal strategy for breeding by combining low-yielding, high-TKW elites with top-yielding but low-TKW ones.

\section{Grouping of Stations into Agroenvironmental Sets}

As indicated, GY, DtH, and PLH had no evident interaction. The use of the performances of the genotypes for these traits is therefore a valid strategy to assess agroenvironmental similarities among stations. In fact, although GY is a result of the yield potential of the varieties and their response to a combination of all climatic effects and biotic stresses, DtH is more directly controlled by the interaction between few genes, daylength, and temperatures (Villegas et al., 2015; Zheng et al., 2016), while for PLH, a set of different genes would interact with moisture availability at the beginning of the season (Choudhury and Kumar, 1980; Wu et al., 2010). Four major groups were found using hierarchical clustering among correlations for these traits at 21 stations. The remaining six 1 stations were integrated into these groups on the basis of their GY correlations alone. Group 1 was represented by the station of Foggia (Italy) 
alone, where the combinations of unique diseases, soil types, temperatures, and rainfall caused the genotypes to perform in a different manner than in any other stations. Group 2 spans Ethiopia, North Africa, and West and Central Asia. It is hard to establish a simple explanation for this cluster, as the six stations experience what appear as different conditions. Days to heading ranged from $60 \mathrm{~d}$ in Ethiopia to $152 \mathrm{~d}$ in Algeria; similar large variations can be observed for all other traits, and disease races can also be expected to be different. The GY of each station of this group is below the overall average, and this might be the reason for their clustering, meaning that the combination of the various stresses imposed on the genotypes had an effect that was overall similar. Margherita was the best-performing elite within this group. Group 3 is also extremely wide, grouping together the top-yielding station (Sids, Egypt) with the lowest-yielding location (Swift Current, Canada). It also includes two of the most unique environments of this study, such as the warm conditions throughout the season of Fanaye (Senegal) and the cultivation in residual monsoon moisture of Amlah (India). Considering the specific stations, the only similarity might be found on the type of agronomical practices followed, since Obregon, Amlah, Fanaye, Sids, and Marchouch are all under the control of CGIAR centers that apply best agronomical practices, whereas Ecija, Swift Current, Eleftere, and Moghan are located in developed countries and Oued Smar is the flag station of the national breeding program of Algeria, where best practices are also applied. Margherita is again the bestperforming elite for this group by far.

Group 4 clusters together three environments from Lebanon, two environments from Algeria, the main station of CIMMYT in Obregon, and four drought stations from Portugal, Azerbaijan, Jordan, and Morocco. In this case, geographical similarity might be the best explanation for their grouping into a single cluster, even though large variation exists in terms of overall performances of the single stations. For this group, Margherita and Ouassara1 are the best-performing elites. Interestingly, Margherita appears as the best-performing line at both the flag stations of CIMMYT in Obregon and of ICARDA in Terbol.

\section{Performances of Germplasm Based on Selection Indices}

The genotypes were exposed to severely contrasting agroenvironmental conditions, as showed by the clustering analysis. Among the differences was the exposure to different virulent races of five major diseases affecting durum wheat. In the set of stations analyzed, ST, TS, and PM were the most frequent; YR did not constitute a major treat, whereas LR only mildly affected the 38th IDYT set. A very strict "susceptibility to disease" index was used, and seyeral genotypes maintained good performance. No elite was resistant to all diseases, but Icaverve was the most resistant overall.
Two of the most commonly utilized stability values were used to evaluate the 38th IDYT set (Malosetti et al., 2013). Both $b^{\prime}$ and AWAI confirmed that nearly all elites had good yield stability across the 27 extremely diverse environments used in the analysis. Further, at all stations, with the exclusion of Elvas (Portugal), one or more entries outyielded the national check, confirming that this small set of elites combined both wide and specific adaptation. In fact, the national check is represented by the available commercial cultivar most adapted to each specific environment but, as a consequence, also represents a very stable genotype when considered across sites, since its value is represented by several different cultivars, all adapted. Surpassing this check indicates excellent stability, as well as yield potential.

Selection indices have been widely used to improve trait combinations on breeding schemes (Branlard et al., 1992; Sharma and Duveiller, 2003) and more recently in genomic selection strategies (Heffner et al., 2011; Bassi et al., 2016). The implementation of two selection strategies was deployed for identifying high-yielding and stable genotypes. Three top elites were singled out that could not be recognized based on yield data alone. These results confirm that selection indices are useful to capture unique trait combinations for variety selection. In terms of performances, these three top lines show similar phenological pattern, with each flowering and maturing around the average time and a slight tendency towards extended GFP. However, their response for TKW is very different from the maximum (45 g, Derazejihan) and minimum (39 g, Kundermiki) scores overall. Finally, two of them showed good disease resistance, whereas the third was susceptible to nearly all diseases tested. More surprisingly, the two most successful elites (Margherita and Ouassara3) were excluded from the top list and were identified only by the $b^{\prime}$ index. Both genotypes tend to flower early, mature around the average time, have an extended GFP, and have identical medium-size PLH. Additionally, Margherita shows resistance to PM and LR. In particular, Margherita was the top yielder in some of the most stressed stations, such as Erbil (Iraq) of Group 2 and in Obregon with reduced drip irrigation (Mexico) of Group 3, while at the same time winning at some of the top-yielding stations of Group 4, such as Terbol (Lebanon) and Obregon full irrigation (Mexico). However, the exclusion of these two cultivars from the AWAI index can be traced to their drop in performances in some locations, such as a loss of $70 \%$ compared with the best yielder in Mushagar (Jordan) and 59\% in Gachsaran (Iran) for Margherita, and of 57\% in Sidi el Aidi (Morocco) and 37\% in Bousselham (Algeria) for Ouassara3 (data not shown). In terms of breeding, it is highlighted by these data that stability is not the only criteria for selection, as several environments would benefit from Margherita or Ouassara3, even if it these are not performing well at all locations. The 
$b^{\prime}$ index was less affected by the outlier stations described above and should therefore be preferred over the AWAI index. Nevertheless, the combined use of two indices has allowed the solid identification of three genotypes that are both stable and top yielding. These elites should always be prioritized when possible.

\section{CONCLUSION}

The 38th IDYT shipped from ICARDA was received by 64 collaborators in 32 countries and remain freely available to anybody. This represents a major international effort to distribute useful durum wheat germplasm around the world. The data summarized here shall benefit the international breeding community in terms of identifying ideal crossing material or for direct cultivar release. Further, the use of a clustering method based on correlation for three traits has allowed the identification of unsuspected similarities between 27 stations in 18 countries. This once again shows the importance of combining efforts in breeding and of promoting the unrestricted sharing of germplasm. In addition, the data presented here support the use of this method in future multilocation studies to find unbiased similarities between locations derived from the performances of the genotypes. Moreover, the assessment of two selection indices based on yield stability and yield potential revealed their usefulness and could be integrated in other breeding programs.

\section{Conflict of Interest}

The authors declare that there is no conflict of interest.

\section{Acknowledgments}

The authors wish to thank Dr. Abdelaziz Niane (ICARDA) for coordinating the shipment of the trials, Dr. Pancho Crossa (CIMMYT) and Dr. Michael Baum (ICARDA) for constructive criticism, the station managers, and research scientists that have provided the data analyzed here: Prof N. Pecchioni and Dr. P. de Vita (Foggia, Italy); Mr. L. Wasihun (Debre Zeit, Ethiopia); Dr. M. Roostai and Dr. A. Ghaffari et al. (Gachsaran and Moghan, Iran); Dr. O. Zaghuane et al. (Guelma, El Khroub, Bousselham, and Oued Smar, Algeria); Dr. Y. Shakhatreh (Maru and Mushager, Jordan); Dr. A. Sourour (El Kef, Tunisia); Dr. A. S. Husham (Erbil, Iraq); Dr. Vaios Liotsos (Eleftere, Greece); Dr. S. M. Ragab El-Areed (Sids, Egypt); Mr. A. Sall and Dr. M. Cisse (Fanaye, Senegal); Dr. I. Solis Martell (Ecija, Spain); Dr. Y. Ruan and Dr. S. Barales (Swift Current, Canada); Dr. J. Coutinho (Elvas, Portugal); Dr. N. Naserellah (Sidi El Aidi, Morocco); Dr. R. Kabalan (Tel Amara, Lebanon); Dr. J.M. Talai (Baky, Azerbaijan); Dr. K. Ammar and the CIMMYT team (Obregon, Mexico); R. Abu-Naked (Terbol, Lebanon); A. Rached (Marchouch, Morocco); S. Barpete and Dr. V. Singh (Amlah, India).

\section{References}

Adary, A., A. Hachum, T. Oweis, and M. Pala. 2002. Wheat productivity under supplemental irrigation in Northern Iraq. OnFarm Water Husbandry Res. Rep. 2. ICARDA, Aleppo, Syria.
Al-Issa, T.A., and N.H. Samarah. 2006. Tillage practices in wheat production under rainfed conditions in Jordan: An economic comparison. World J. Agric. Sci. 2:322-325.

Álvaro, F., J. Isidro, D. Villegas, G. del Moral, and C. Royo. 2008. Breeding effect on grain filling, biomass partitioning, and remobilization in Mediterranean durum wheat. Agron. J. 100:361-370. doi:10.2134/agrojnl2007.0075

Bassi, F.M. 2016. A river runs through it: Durum wheat's new home in Senegal and Mauritania. CGIAR. http://dialogues. cgiar.org/blog/durum-wheat-new-home-senegal-mauritania/ (accessed 20 June 2016).

Bassi, F.M., A.R. Bentley, G. Charmet, R. Ortiz, and J. Crossa. 2016. Breeding schemes for the implementation of genomic selection in wheat (Triticum spp.). Plant Sci. 242:23-36. doi:10.1016/j.plantsci.2015.08.021

Bergh, K., A. Chew, M.K. Gugerty, and C.L. Anderson. 2012. Wheat value chain: Ethiopia. Brief 204. Univ. of Washington, Evans School Policy Anal. Res., Seattle, WA.

Blum, A., L. Shpiler, G. Golan, and J. Mayer. 1989. Yield stability and canopy temperature of wheat genotypes under droughtstress. Field Crops Res. 22:289-296. doi:10.1016/03784290(89)90028-2

Bonjean, A.P., W.J. Angus, and M. van Ginkel. 2016. The world wheat book: A history of wheat breeding Vol. 3. Lavoisier, Paris.

Branlard, G., J. Pierre, and M. Rousset. 1992. Selection indices for quality evaluation in wheat breeding. Theor. Appl. Genet. 84:57-64. doi:10.1007/BF00223981

Choudhury, P.N., and V. Kumar. 1980. The sensitivity of growth and yield of dwarf wheat to water stress at three growth stages. Irrig. Sci. 1:223-231. doi:10.1007/BF00277627

De Vita, P., A.M. Mastrangelo, L. Matteu, E. Mazzucotelli, N. Virzi, M. Palumbo et al. 2010. Genetic improvement effects on yield stability in durum wheat genotypes grown in Italy. Field Crops Res. 119:68-77. doi:10.1016/j.fcr.2010.06.016

del Moral, G., Y. Rharrabti, D. Villegas, and C. Royo. 2002. Evaluation of grain yield and its components in durum wheat under Mediterranean conditions. Agron. J. 95:266-274. doi:10.2134/agronj2003.0266

El-Areed, S., M.M. Nachit, A. Hagaras, S. El-Sherif, and M. Hamouda. 2014. Durum wheat breeding for high yield potential in Egypt. In: E. Porceddu, A.B. Damania, C.O. Qualset, editors, Proceedings of the International Symposium on Genetics and Breeding of Durum wheat, Bari, Italy. 27-30 May 2013. Centre international de hautes études agronomiques méditerranéennes, Bari. p. 291-294.

Finlay, K.W., and G.N. Wilkinson. 1963. The analysis of adaptation in a plant breeding programme. Aust. J. Agric. Res. 14:742-754. doi:10.1071/AR9630742

Gauch, H.G., and R.W. Zobel. 1997. Identifying mega-environments and targeting geno- types. Crop Sci. 37:311-326. doi:10.2135/cropsci1997.0011183X003700020002x

Giunta, F., R. Motzo, and M. Deidda. 1993. Effect of drought on yield and yield components of durum wheat and triticale in a Mediterranean environment. Field Crops Res. 33:399-409. doi:10.1016/0378-4290(93)90161-F

Gollob, H.F. 1968. A statistical model which combines features of factor analytic and analysis of variance techniques. Psychometrika/33:73-115. doi:10.1007/BF02289676

Hargreaves, G., G. Hargreaves, and J. Riley. 1985. Agricultural benefits for Senegal River basin. J. Irrig. Drain. Eng. 111:113124. doi:10.1061/(ASCE)0733-9437(1985)111:2(113) 
Heffner, E.L., J. Jannink, and M.E. Sorrells. 2011. Genomic selection accuracy using multifamily prediction models in a wheat breeding program. Plant Genome 4:65-75. doi:10.3835/ plantgenome.2010.12.0029

Isidro, J., F. Alvaro, C. Royo, D. Villegas, D.J. Miralles, and L.F.G. del Moral. 2011. Changes in duration of developmental phases of durum wheat caused by breeding in Spain and Italy during the 20 th century and its impact on yield. Ann. Bot. (Lond.) 107:1355-1366. doi:10.1093/aob/mcr063

Juarez, B., and D. Wolf. 2015 Mexico: Grain and feed annual. USDA Foreign Agric. Serv., Washington, DC.

Karabina, K., and E. Leonardi. 2016. Turkey grain and feed annual report. TR6015. USDA Foreign Agric. Serv., Washington, DC.

Karam, F., R. Kabalan, J. Breidi, Y. Rouphael, and T. Oweis. 2009. Yield and water-production functions of two durum wheat cultivars grown under different irrigation and nitrogen regimes. Agric. Water Manage. 96:603-615. doi:10.1016/j. agwat.2008.09.018

Kumari, M., R.N. Pudake, V.P. Singh, and A.K. Joshi. 2013. Association of staygreen trait with canopy temperature depression and yield traits under terminal heat stress in wheat (Triticum aestivum L.). Euphytica 190:87-97. doi:10.1007/s10681-0120780-3

Le Lamer, O., and X. Rousselin. 2011. The durum wheat market. In: F. Bova, editor, Studies of FranceAgriMer. FranceAgriMer, Montreuil-sous-Bois, France. p. 1-46.

Maccaferri, M., M.C. Sanguineti, S. Corneti, J.L.A. Ortega, M.B. Salem, J. Bort et al. 2008. Quantitative trait loci for grain yield and adaptation of durum wheat (Triticum durum Desf.) across a wide range of water availability. Genetics 178:489511. doi:10.1534/genetics.107.077297

Malosetti, M., J.M. Ribaut, and F.A. van Euwijk. 2013. The statistical analysis of multi-environment data: Modeling genotype-by-environment interaction and its genetic basis. Front. Physiol. 4:1-17. doi:10.3389/fphys.2013.00044

Marti, J., and G.A. Slafer. 2014. Bread and durum wheat yields under a wide range of environmental conditions. Field Crops Res. 156:258-271. doi:10.1016/j.fcr.2013.10.008

Nagarajan, S. 2006. Quality characteristics of Indian wheat. In: L. Popper, W. Schäfer, and W. Freund, editors, Future of flour. AgriMedia GmbH., Clenze, Germany. p. 79-86.

Pacheco, A., M. Vargas, G. Alvarado, F. Rodríguez, J. Crossa, and J. Burgueño. 2016. GEA-R (genotype $\times$ environment analysis with $\mathrm{R}$ for Windows). Version 2.0. CIMMYT. http://hdl. handle.net/11529/10203 (accessed 20 June 2016).

Payne, R.W., S.A. Harding, D.A. Murray, D.M. Soutar, D.B. Baird, S.J. Welham et al. 2006. GenStat Release 9 reference manual, Part 2: Directives. VSN Int., Hemel Hempstead, UK.

Perkins, J.M. 1972. The principal component analysis of genotype $\times$ environmental interaction and physical measures of environment. Heredity 29:51-70. doi:10.1038/hdy.1972.64

Peterson, R.F., A.B. Campbell, and A.E. Hannah. 1948. A diagrammatic scale for estimating rust intensity of leaves and stems of cereals. Can. J. Res. 26c:496-500. doi:10.1139/ cjr48c-033

R Development Core Team. 2011. R: A language and environment for statistical computing. R Foundation for Statistical Computing, Vienna.

Ranieri, R. 2015. Geography of the durum wheat crop. Pastaria Int. 6:24-36.
Royo, C., F. Álvaro, V. Martos, A. Ramdani, J. Isidro, D. Villegas, and L.F. García del Moral. 2007. Genetic changes in durum wheat yield components and associated traits in Italian and Spanish varieties during the 20th century. Euphytica 155:259-270. doi:10.1007/s10681-006-9327-9

Saari, E.E., and J.M. Prescott. 1975. A scale for appraising the foliar intensity of wheat diseases. Plant Dis. Rep. 59:377-380.

Sabaghnia, N., S.H. Sabaghpour, and H. Dehghani. 2008. The use of an AMMI model and its parameters to analyze yield stability in multi-environment trials. J. Agric. Sci. 146:571-581. doi:10.1017/S0021859608007831

Salem, B.B. 1989. Arid zone forestry: A guide for field technicians (no. 20). FAO, Rome.

Sanchez-Garcia, M., F. Álvaro, J.A. Martín-Sánchez, J.C. Sillero, J. Escribano, and C. Royo. 2012. Breeding effects on the genotype $\times$ environment interaction for yield of bread wheat grown in Spain during the 20th century. Field Crops Res. 126:79-86. doi:10.1016/j.fcr.2011.10.001

Sharma, R.C., and E. Duveiller. 2003. Selection index for improving Helminthosporium leaf blight resistance, maturity, and kernel weight in spring wheat. Crop Sci. 43:2031-2036. doi:10.2135/cropsci2003.2031

Sneller, C.H., L. Cilgore-Norquest, and D. Dombek. 1997. Repeatability of yield stability statistics in soybean. Crop Sci. 37:383390. doi:10.2135/cropsci1997.0011183X003700020013x

Statistics Canada. 2016. Estimated areas, yield, production and average farm price of principal field crops. Field Crop Reporting Series. Statistics Canada, Ottawa, ON.

Subira, J., F. Alvaro, L.F.G. del Moral, and C. Royo. 2015. Breeding effects on the cultivar $\times$ environment interaction of durum wheat yield. Eur. J. Agron. 68:78-88. doi:10.1016/j. eja.2015.04.009

Villegas, D., C. Alfaro, K. Ammar, M.M. Cátedram, J. Crossa, L.F.G. del Moral, and C. Royo. 2015. Daylength, temperature and solar radiation effects on the phenology and yield formation of spring durum wheat. J. Agron. Crop Sci. 202:203216. doi:10.1111/jac. 12146

Voltas, J., H. López-Córcoles, and G. Borrás. 2005. Use of biplot analysis and factorial regression for the investigation of superior genotypes in multi-environment trials. Eur. J. Agron. 22:309-324. doi:10.1016/j.eja.2004.04.005

Wiegand, C.L., and J.A. Cuellar. 1980. Duration of grain filling and kernel weight of wheat as affected by temperatures. Crop Sci. 21:95-101. doi:10.2135/cropsci1981.0011183X001100010027x

Wu, X., Z. Wang, X. Chang, and R. Jing. 2010. Genetic dissection of the developmental behavior of plant height in wheat under diverse water regimes. J. Exp. Bot. 61:2923-2937. doi:10.1093/jxb/erq117

Yan, W., L.A. Hunt, Q. Sheng, and Z. Szlavnics. 2000. Cultivar evaluation and mega-environment investigation based on the GGE biplot. Crop Sci. 40:597-605. doi:10.2135/ cropsci2000.403597x

Zadoks, J.C., T.T. Chang, and C.F. Konzak. 1974. A decimal code for growth stages of cereals. Weed Res. 14:415-421. doi:10.1111/j.1365-3180.1974.tb01084.x

Zheng, B., K. Chenu, and S.C. Chapman. 2016. Velocity of temperature and flowering time in wheat: Assisting breeders to keep pace with climate change. Glob. Change Biol. 22:921933. doi:10/111/geb. 13118 A

Zobel, R.W., M.J. Wright, and H.G. Gauch. 1988. Statistical analysis of a yield trial. Agron. J. 80:388-393. doi:10.2134/agronj 1988.00021962008000030002x 